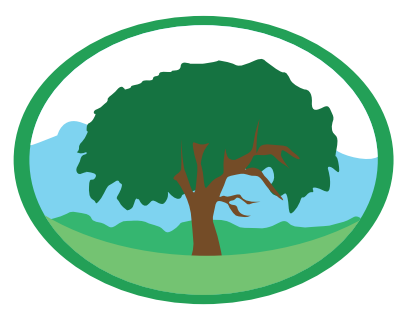

\title{
ALTERNATIVA PARA CONTROLE DE PLANTAS DANINHAS POR MEIO DE CAPINA ELETRICA EM SISTEMAS SILVICULTURAIS
}

\author{
MEDAUAR, C. C. ${ }^{1}$; GALVÃO, I. M. ${ }^{2}$; CARVALHO, L. C. C. ${ }^{3}$; SILVA, S. DE. A. ${ }^{4}$. \\ 'Doutorando do Programa de Pós-Graduação em Produção Vegetal, Departamento de Ciências Agrárias e Ambientais, UESC, Ilhéus- \\ BA \\ ${ }^{2}$ Mestrando do Programa de Pós-Graduação em Agronomia (Irrigação e Drenagem), Departamento de Engenharia Rural, UNESP, \\ Botucatu-SP \\ ${ }^{3}$ Professor, Departamento de Ciências Agrárias e Ambientais, UESC, Ithéus-BA \\ ${ }^{4}$ Professor, Departamento de Engenharia Rural, UFES, Alegre-ES
}

Palavras-chave: ambiente, sustentabilidade, tecnologia.

\begin{abstract}
Resumo
Com este trabalho se objetivou argumentar o uso da tecnologia de capina elétrica para dessecação e/ou controle de plantas daninhas no sistema de silvicultura, auxiliando nas medidas para conservações do meio ambiente como alternativa ecológica. A revisão destaca a tecnologia de aplicação atual na silvicultura, os principais métodos de combate às plantas daninhas, até chegar ao funcionamento da capina elétrica. Foram relatadas as principais características, funcionamento e algumas hipóteses para inserção ou não do equipamento para a silvicultura. A atividade da capina elétrica na silvicultura em determinada região e época do ano é inviável em relação a critérios técnicos e ecológicos, devido aos riscos de incêndios quando se tem muita matéria seca sobre o solo.
\end{abstract}

\section{ALTERNATIVE FOR WEED CONTROL BY ELECTRIC WEDDING IN FORESTRY SYSTEMS}

Keywords: environment, sustainability, technology.

\begin{abstract}
The aim of this study was to argue the use of electric weeding technology for desiccation and/or weed control in the forestry system, aiding in measures for environmental conservation as an ecological alternative. The review highlights the current application technology in forestry, the main methods of weed control, until it reaches the function of the electric weeding. The main characteristics, functioning and some hypotheses for the insertion or not of forestry equipment have been reported. The activity of electric weeding in forestry in a given region and time of year is unviable in relation to technical and ecological criteria, due to the risk of fire when there is a lot of dry matter on the soil.
\end{abstract}




\section{INTRODUÇÃO}

Nos últimos anos o desenvolvimento da tecnologia para a silvicultura no Brasil vem em constante progressão, aliado as condiçóes naturais favoráveis, aos menores custos de implantaçáo de florestas plantadas, além do grande mercado exportador de produtos madeireiros (Medauar, 2017). Em uma exploração florestal são necessários investimentos em tecnologia de maquinários e implementos agrícolas para que possa aproveitar melhor o tempo de operação e redução da mão de obra (Ruas et al., 2014).

Assim, com o avanço da tecnologia as funçóes conjuntas de mapeamento e descrição das principais operaçôes, caracterização da área de estudo e movimentos das etapas operacionais que visam os métodos de eficiências e rendimentos tem alta importância no setor silvicultural (Hakamada, 2012). Essas características implicam na melhoria de qualidade, planejamento e organização das atividades.

No setor silvicultural a eficiência da pulverização de agrotóxicos está associada a diversos fatores, como: condiçôes meteorológicas, volume de calda do produto, tecnologia de aplicação, estado fenológico da espécie e estrutura do dossel (Tiburcio, 2014). A falta de combinação desses fatores podem resultar em uma baixa eficácia do produto a ser aplicado (Llorens et al., 2010).

Rodrigues et al. (2008), afirmam que independente do processo utilizado nas operaçóes de combate a plantas daninhas, o ideal é estruturar métodos, que sirvam de base para avaliar e controlar o procedimento de aplicação, garantindo dessa forma, o mínimo de dano ao homem e meio ambiente.

O investimento na silvicultura, liderado por grandes empreendimentos do segmento de papel e celulose, tem-se aumentado com a demanda da diversificação de tecnologias inovadoras por parte de implementos agrícolas (Carvalho \& Bajay, 2006).

A demanda por maquinários modernos no sistema silvicultural são de grande importância para o uso conservacionista do meio ambiente e a interação da máxima eficiência econômica associada com a elevada produção (Ruas et al., 2014), sendo assim, o principal interesse no mercado florestal brasileiro.

Com isso, a capina elétrica (Eletroherb) surge como inovação no país em relação ao controle de plantas daninhas na silvicultura, uma vez que esse implemento é bastante utilizado na limpeza de cidade, atuando principalmente em ruas, meios fios e calçadas e em meio agrícola atuando em cultivos orgânicos e culturas permanentes (Brighenti \& Brighenti, 2009).

O uso dessa tecnologia nos últimos anos vem sendo adaptado para atuar no segmento florestal, na atividade de combate a plantas daninhas com o intuito de substituir parcialmente e/ou totalmente os agrotóxicos. Partindo desse pressuposto, essa substituição visa alavancar as empresas e produtores em relaçáo as novas tendências do mercado em pró da exigência das certificaçóes, questionadas pelas auditorias (Tessaro et al., 2013).

Diante do exposto, o objetivo do trabalho foi argumentar o uso da tecnologia de capina elétrica para dessecação e/ou controle de plantas daninhas no sistema de silvicultura, auxiliando nas medidas para conservaçóes do meio ambiente como alternativa ecológica.

\section{TEMAS DA REVISÃO}

\section{Tecnologia de aplicação de produtos químicos na silvicultura}

Uma adequada e correta tecnologia de aplicação de agrotóxicos, segundo Matthews (2002), é aquela que visa inserir a quantidade certa de ingrediente ativo no alvo, com maior margem de eficiência, além de priorizar um alto índice de uniformidade, atrelando a máxima eficácia econômica e o menor impacto ao meio ambiente. Minguela \& Cunha (2010), comentam que é importante a aplicação de agroquímicos de forma racional, dentro do contexto mais amplo do manejo integrado.

Entretanto, existem componentes da pulverização, como a cobertura e à deriva, que não conseguem atingir o alvo requerido com elevada percentagem de erradicação. A deriva é uma das principais formas de perda de agrotóxicos, com desperdício de insumos, menor eficiência e danos econômicos ao ambiente, devido à contaminação do ar, solo e água (Oliveira et al., 2013).

Além da tecnologia de aplicação, outros fatores como 
as características do ambiente, condiçôes climáticas e propriedades físico-químicas dos compostos, influenciam a qualidade da aplicação (Schampheleire et al., 2008). Esses fatores são cruciais na área florestal, principalmente em talhôes para reversão, onde se busca a erradicação das brotaçóes do ciclo anterior.

Quando esta etapa é feita por meio químico, existe a necessidade de monitoramento, ao longo do tempo, do estado destas brotaçóes, visando à avaliação da eficácia de controle e orientando a tomada de decisão sobre a necessidade de novas aplicaçóes ou adoção de nova metodologia para controle (Medauar, 2017).

Tendo em base que na área florestal há uma grande quantidade de resíduos que comprometem a passagem de algumas máquinas, um dos grandes desafios da aplicação de produtos químicos em florestas plantadas é manter o volume de pulverização constante, mesmo com a elevada variação de velocidade de deslocamento dos pulverizadores. Outro ponto importante é que a infestação na área plantada nem sempre ocorre de maneira uniforme, isto é, a aplicação em área total quase sempre acarreta desperdício de produto (Gurgacz, 2013).

\section{Métodos de controle das plantas daninhas no sistema silvicultural}

Entre os métodos de controle de plantas daninhas, o mecânico (roçadoras e destocadores) e o químico (agrotóxicos) são os mais utilizados na área florestal. Gonçalves et al. (2011), afirmam que a opção pelo método do controle químico comparado ao controle mecânico é mais vantajoso, ainda mais quando se analisa fatores como: economia de custos com mão de obra e rapidez na obtenção de resultados.

Sabe-se, que a aplicação de defensivos agrícolas se eleva cada vez mais no sistema silvicultural, e consequentemente a este fato, há uma grande cobrança da sociedade por manejo mais sustentável, dentro de um consenso de proteção integrada de plantas com o intuito de evitar a contaminação do solo, da água e os consequentes danos à saúde humana (Rodrigues et al., 2015).

De acordo com Machado et al. (2010), o tratamento químico é o mais utilizado no controle de brotações. Para isso, é recomendada a utilização de herbicidas sistêmicos, que vão translocar para outras partes da planta. O glyphosate é o herbicida mais utilizado na área florestal que pertence ao grupo químico dos aminoácidos fosfonados, tendo como precursor a glicina (Tiburcio, 2014).

A absorção do glifosato por parte do órgão vegetal abrange a penetração inicial por meio da cutícula e da absorção simplástica, sendo o tempo dessa fase dependente da espécie em questão, das condiçóes do ambiente, da idade da planta e da composiçáo do herbicida, entre outros (Silva et al., 2007).

Posteriormente ao processo de absorção, é necessário o transporte do herbicida, por meio de tecido vasculares, até os sítios de ação, o qual vai ser o momento que irá desempenhar sua tarefa (Satichivi et al., 2000). Para apresentar elevada eficácia, o herbicida deve ser depositado no alvo na quantidade correta e proporcionar cobertura e distribuiçáo o mais uniforme possível, na faixa tratada (Tiburcio, 2014).

Os pulverizadores hidráulicos de barras são as máquinas mais utilizadas na aplicação dos agrotóxicos, e a escolha e forma de uso desses equipamentos são fundamentais para que se obtenha ação eficaz (Dornelles et al., 2009). Além disso, atua no mercado florestal o pulverizador autopropelido, também chamados de pulverizadores automotrizes ou autopropulsados, como exemplo o modelo 4630 da empresa John Deere.

Devido à falta de implementos específicos, os equipamentos utilizados na área florestal são, em sua maioria, adaptaçóes dos utilizados em cultivos agrícolas, o que, muitas vezes, é realizada de maneira inadequada devido à falta de conhecimento de fatores como a correta pressão de trabalho, a altura da ponta em relação ao alvo, espaçamento entre pontas, combinação apropriada entre pontas, faixa de aplicação uniforme e rendimento operacional (Viana et al., 2010).

Em algumas regióes do Brasil o controle de ervas daninhas é complexo devido à precipitação pluviométrica bem distribuída o que compromete em algumas épocas do ano a utilização dos herbicidas (Tiburcio, 2014).

Nesse contexto, torna-se fundamental a inserção de técnicas de engenharia na produção das máquinas específicas ao setor florestal, em vez da adaptação de equipamentos agrícolas (Orlanda, 2013). 


\section{Capina elétrica (Eletroherb)}

A Sayyou Brasil, desenvolveu uma tecnologia de controle de plantas daninhas denominada Eletroherb a qual proporciona uma tecnologia que insere no mercado um novo conceito de capina elétrica, eliminando as plantas daninhas com choques elétricos (Brighenti \& Brighenti, 2009).

Aplica-se uma corrente com alta amperagem dessecando o sistema orgânico e impedindo a condução da seiva pelo sistema interno da planta. Dessa forma tanto o sistema aéreo (folhas e caules) quanto o sistema radicular (raízes) são eliminados (Brighenti \& Brighenti, 2009).

O uso da capina elétrica possui a aprovação e certificação do Instituto de Biodinâmica (IBD), o qual lhe fornece permissão para atuar na agricultura orgânica, tradicional e em segmentos florestais (Brighenti \& Brighenti, 2009).

\section{Funcionamento da capina elétrica}

O funcionamento do Eletroherb é composto por um sistema que é ativado pela tomada de potência determinando uma frequência de $65 \mathrm{~Hz}$ ao gerador da capina elétrica. $\mathrm{O}$ movimento rotacional garante a extração de uma energia potencial do motor diesel do trator com o intuito de alcançar $60 \mathrm{~kW}$ de energia elétrica (Landers et al., 2016).

Esta mesma energia alcançada de $440 \mathrm{~V}$ incide em um indutor trifásico, o qual possui as funçóes de não deixar o alternador do sistema passar por problemas de correntes e também de regularizar o total funcionamento do motor. Além disso, a própria corrente elétrica tem a capacidade de fornecer energia para cada transformador, onde cada um desses transformadores tem a possibilidade de alterar a tensão de $440 \mathrm{~V}$ até $15.000 \mathrm{~V}$ (Landers et al., 2016).

Todo este sistema da capina elétrica é controlado para promover a maior eficiência de aplicação na operação. Portanto, o funcionamento do sistema elétrico é realizado pelos aplicadores (palhetas) que são os polos positivos e o outro aplicador (discos) sendo negativos (Landers et al., 2016).

O polo positivo entra em contato direto com as ervas daninhas e o negativo em contato diretamente com o solo, garantindo a atração no sistema. Além disso, o Eletroherb não é seletivo, erradicando as folhas estreitas e largas entre 15 e $45 \mathrm{~cm}$ de altura e sua faixa de aplicação é de 2,4 $\mathrm{m}$ na linha de plantio (Landers et al., 2016).

\section{Hipóteses para inserção do Eletroherb na silvicultura}

OBrasil é o segundo mercado e um dos maiores importadores de agrotóxicos por hectare do mundo, sendo os herbicidas e inseticidas responsáveis por grande parte dos produtos comercializados no país (Pelaez et al., 2015).

É realmente discrepante a ação do uso excessivo de defensivos agrícolas no Brasil, causando o desbalanceamento da cadeia alimentar dos seres vivos, esterilização do solo, destruição da vida aquática, poluiçáo dos rios e nascentes e principalmente a contaminação dos lençóis freáticos (Oliveira et al., 2009).

A ação deste implemento de capina elétrica na silvicultura depende diretamente de uma Licença Ambiental Simplificada (LAS), com habilitação neste tipo de trabalho e também de uma autorização ambiental específica, na presença de um engenheiro responsável e prazo de validade da atividade (Tessaro et al., 2013).

Entretanto, de acordo com o funcionamento do Eletroherb, a operação é realizada com alta potência de energia elétrica, o qual pode gerar um grave problema, que é o risco de incêndio. Os incêndios florestais podem acarretar em perdas essenciais no ecossistema e ambiente, como prejuízos à fauna e flora, destruição de habitats, queima de árvores e madeira, além do uso da água para controlar o fogo (Fiedler et al., 2006).

Em alguns períodos do ano de climas secos, elevadas temperaturas e baixa velocidade do vento, a operação da capina elétrica poderá ser inapropriada e altamente perigosa (Tebaldi et al., 2013).

Inicialmente, a solução mais viável e ecológica para evitar os riscos de incêndios com o uso da capina elétrica, seria estabelecer através de séries históricas e testes em campo, sistemas de previsão ou padróes de variáveis climáticas favoráveis a atividade (Lima, 2013), promovendo a inserção da capina elétrica em períodos específicos.

Partindo do pressuposto da solução descrita 
anteriormente, uma alternativa também plausível para evitar os riscos de incêndios é através de mapas de zonas de risco, os quais são utilizados para definir o zoneamento climático, indicando épocas e áreas geográficas menos favoráveis para a atividade da capina elétrica (Canteri et al., 2007).

\section{CONCLUSÃO}

1. A atividade da capina elétrica na silvicultura em determinada região e época do ano é inviável em relação a critérios técnicos e ecológicos, devido aos riscos de incêndios quando se tem muita matéria seca sobre o solo.

2. É importante o estudo de tecnologias que priorizem a redução de impactos ambientais na atividade de controle de plantas daninhas para os sistemas silviculturais.

\section{LITERATURA CITADA}

Brighenti, A. M.; Brighenti, D. M. Controle de plantas daninhas em cultivos orgânicos de soja por meio de descarga elétrica. Ciência Rural, v. 39, n. 8, p. 2315-2319, 2009.

Canteri, M. G.; Del Ponte, E. M.; Godoy, C. V.; Tsukahara, R. Y. Emprego da tecnologia da informação para simulação de epidemias e zoneamento agroclimático aplicáveis no controle de doenças de plantas. Summa Phytopathologica, v. 33, p. 104-160, 2007.

Carvalho, C. B.; Bajay, S. V. O setor agropecuário no estado da bahia: perspectivas econômicas e intensidade energética. Núcleo Interdisciplinar de Planejamento Energético do Departamento de Energia / FEM, Universidade Estadual de Campinas, Campinas, SP, 2006.

Dornelles, M. E.; Schlosserll, J. F.; Casali, A. L.; Brondanil, L. B. Inspeção técnica de pulverizadores agrícolas: histórico e importância. Ciência Rural, v. 39, n. 5, p. 1600-1605, 2009.

Fiedler, N. C.; Rodrigues, T. O.; Medeiros, M. D. Avaliação das condiçôes de trabalho, treinamento, saúde e segurança de brigadistas de combate a incêndios florestais em unidades de conservação do Distrito Federal-estudo de caso. Revista Árvore, v. 30, n. 1, p. 55-63, 2006.

Gonçalves, K. S.; São José, A. R.; Cavalieri, S. D.; Martins, I. S. B.; Velini, E. D. Seletividade de herbicidas aplicados em pós-emergência em pinhão manso (Jatropha curcas L.). Revista Brasileira de Herbicidas, v. 10, n. 2, p. 110-120, 2011.

Gurgacz, F. Utilização de barra auxiliar de pulverização de água para reduzir a deriva de defensivos agrícolas. 2013. 53 f. Tese (Doutorado) - Universidade Estadual Paulista, Botucatu, SP, 2013.

Hakamada, R. E. Uso do inventário florestal como ferramenta de monitoramento da qualidade silvicultural em povoamentos clonais de Eucalyptus. 2012. 115 p. Dissertação (Mestrado) ESALQ/USP, Piracicaba, 2012.
Landers, J. N.; Challiol, M.; Vilela, L.; Lanz, S. Case study of zero-tillage organic soybean production in Brazil. Soil Research, v. 54, n. 2, p. 166-172, 2016.

Lima, L. L. Aspectos epidemiológicos da ferrugem alaranjada da cana-de-açúcar (Puccinia kuehnii). 2013. 65 p. Tese de doutorado (Doutorado em Agronomia). Universidade Estadual Paulista, Jaboticabal, 2013.

Llorens, J.; Gil, E.; Llop, J.; Escolà, A. Variable rate dosing in precision viticulture: use of electronic devices to improve application efficiency. Crop Protection, v. 29, n. 3, p. 239-248, 2010.

Machado, A. F. L. Ferreira, L. R.; Santos, L. D. T.; Ferreira, F. A. Interferência de plantas daninhas na cultura do eucalipto. Manejo integrado de plantas daninhas na cultura do eucalipto. Viçosa, MG: DFT/UFV, p. 15-37, 2010.

Matthews, G. A. Pesticide application methods. 3. ed. London: Blackwell, p. 432, 2002.

Medauar, C. C. Eficiência de aplicação de herbicidas e monitoramento de brotaçóes de eucalipto utilizando imagens aéreas. 2017. 86f. Dissertação (Mestrado em Produção Vegetal) Universidade Estadual de Santa Cruz, UESC, Ilhéus, 2017.

Minguela, J. V; Cunha, J. A. R. Manual de Aplicação de Produtos Fitossanitários. p. 588, 2010.

Oliveira, E. de.; Maggi, M. F.; Matos, E. de.; Ramos, M. S. de.; Vagner, M. W.; Lopes, E. C. Technology of application of agricultural defensives and relations with the risk of contamination of the water and the soil. Applied Research \& Agrotechnology, v. 2, n. 3, p. 161-180, 2009.

Oliveira, R. B.; Antuniassi, U. R.; Mota, A. A. B.; Chechetto, R. G. Potential of adjuvants to reduce drift in agricultural spraying. Engenharia Agrícola, v. 34, p. 986-992, 2013.

Orlanda, F. J. Q. Desenvolvimento de máquinas e de implementos para o preparo de solo e plantio. Série Técnica IPEF, Piracicaba, SP, n. 38, 2013.

Pelaez, V. M.; Silva, L. R. da; Guimarães, T. A.; Ri, F. D.; Teodorovicz, T. A (des) coordenação de políticas para a indústria de agrotóxicos no Brasil. Revista Brasileira de Inovação, v. 14, p. 153-178, 2015.

Rodrigues, E. B.; Abi-Saab, O. J.; Gandolfo, M. A.; de Oliveira, R. B.; Hasegawa, M. M. Deriva de equipamentos costais na aplicação de glyphosate. Revista Brasileira de Engenharia Agrícola e Ambiental, v. 19, n. 10, p. 1012-1017, 2015.

Rodrigues, G. J.; Teixeira, M. M.; Filho, E. I. F.; Picanço, M. C. Características do fluxo de ar de um pulverizador hidropneumático para aplicação de agroquímicos em plantas arbustivas. Engenharia na Agricultura, v. 16, n. 2, p. 199-207, 2008.

Ruas, R. A. A.; Dezordi, L. R.; Fernandes, H. C.; Leite, E. S.; Vieira, G. P. Silvicultura de Precisão na Eucaliptocultura. Eucaliptocultura no Brasil: Silvicultura, Manejo e Ambiência. Viçosa, MG, cap. 13, p. 274, 2014.

Satichivi, N. M.; Wax, L. M.; Stoller, E. W.; Briskin, D. P. Absorption and translocation of glyphosate isopropylamine and trimethysulfonium salts in Abutilon theophrasti and Setaria faberi. Weed Science, v. 48, n. 6, p. 675-679, 2000.

Schampheleire, M.; Nuyttens, D.; Baetens, K.; Cornelis, W.; Gabriels, D.; Spanoghe, P. Effects on pesticide spray drift of the physicochemical properties of the spray liquid. Precision Agriculture, Bedford, v. 9, p. 1-12, 2008.

Silva, J. F.; Silva, J. F. da; Ferreira, L. R.; Ferreia, F. A. Herbicida: absorção, translocação, metabolismo, formulação e misturas. In: SILVA, A. A.; SILVA, J. F. Tópicos em manejo de plantas 
daninhas. Viçosa, MG: Editora UFV, p. 367, 2007.

Tebaldi, A. L. C.; Fiedler, N. C.; Juvanhol, R. S.; Dias, H. M. Açóes de prevenção e combate aos incêndios florestais nas unidades de conservação estaduais do Espírito Santo. Floresta e Ambiente, v. 20, n. 4, p. 538-549, 2013.

Tessaro, A. B.; Pedrazzi, C.; Tessaro, A. A. Importância da Auditoria Ambiental em Indústrias de Celulose e Papel. Revista de Gestão Ambiental e Sustentabilidade: GeAS, v. 2, n. 2, p. 104124, 2013.

Tiburcio, R. A. S. Desenvolvimento de pulverizador visando o controle de brotaçóes na reforma de eucalipto. 2014. 83 p. Tese de doutorado (Doutorado em Engenharia Agrícola). Universidade Federal de Viçosa, Viçosa, 2014.

Viana, R. G.; Ferreira, L. R.; Rosell, J. R.; Solanelles, F.; Filat, A.; Machado, M. S.; Machado, A. F. L.; Silva, M. C. C. Liquid distribution of air induction and off-center spray nozzles under different conditions. Planta Daninha, v. 28, n. 2, p. 429-437, 2010 . 